\title{
The Possible Success Factors of Introduction of CRM System at Hungarian SMEs
}

\author{
Regina Reicher ${ }^{1}$, Nándor Komáromi ${ }^{2}$, Ágnes Szeghegyi ${ }^{1}$ \\ ${ }^{1}$ Óbuda University, Keleti Faculty of Business and Management, Institute of \\ Enterprise Management, Tavaszmező u. 17, H-1084 Budapest, Hungary \\ reicher.regina@kgk.uni-obuda.hu; szeghegyi.agnes@kgk.uni-obuda.hu \\ ${ }^{2}$ Szent István University, Faculty of Economics and Social Sciences, Institute of \\ Business Studies, Páter K. utca 1, H-2100 Gödöllő, Hungary \\ komaromi.nandor@gtk.szie.hu
}

\begin{abstract}
The information technology projects within companies often end with failure. It may be due to various reasons, but the human factor almost always can be blamed. The organizations, as groups or staff communities, frequently resist change and the introduction of CRM systems can lead to significant corporate changes.

A smaller team should participate in the selection and implementation of a CRM IT system. Our research focuses on the competencies required in the course of an implementation and the impact they may have on the decisions, within the process. We tried to explore the possible correlation, with the "index of success", if the stakeholders in the implementation can be arranged in well-defined segments, on the basis of specific factors.

According to our results, the pairing specific factors can lead to a more successful project implementation and it is worth priority consideration, as the main factors when setting up the team.
\end{abstract}

Keywords: CRM implementation; CRM selection; factors affecting successful implementation; SME

\section{Introduction}

An organization is operated through human activities. The people working in the organization need information for their activities, as well as, for the coordination and harmonization of their cooperation. A basic objective for companies and organizations is to make a profit by fulfilling the needs of the consumer. This basic objective defines which consumers, which of their needs can be satisfied and with what kind of process, internal operation and environmental relations. [5] 
Many papers written in the recent years indicate that only $30 \%$ of organizations introducing a CRM technology achieved some improvement in corporate performance. The research made by Chang et al has proved that the purchase of CRM technology is necessary but not sufficient condition of successful CRM implementation. [4]

Therefore, we regarded it necessary to examine how the two participants in the implementation, namely the supplier and the purchaser, manage the process. What are the competencies of those who participate in the project on behalf of the organization? How these competencies complement each other, how they affect the process of selection and implementation? Szabó reveals, in a research paper, that the innovation activities of the Hungarian SMEs lag behind and need significant improvement compared to those in other countries. [10]

It is inevitable for the introduction of CRM systems that the organization, itself become, client-oriented. It means that the organizational hierarchy should be considerably different from a traditional organizational structure. According to Rust [7], the responsibilities should be re-defined because it is important that everybody is completely aware of their tasks. A new position is announced, namely the client manager, who has operative responsibilities with an appropriate authorization. The work of client manager includes strategic planning, fulfillment and monitoring of client-side functions. It is especially important to modify the organization structure which obstructs the information flow.

\section{Strategy}

Of course, the new organization will not be self-established. An organization very rarely wants to change itself. These types of organizational restructuring occur mostly due to external forces or pressure from above. In this kind of a radical change, the development and implementation of a new strategy requires set up of a new organizational structure and the introduction of a new corporate culture and development of a new incentive system. These are the tasks of the top management.

The appropriate handling of possible negative reactions, should always be given attention, in the course of planning and managing the organizational development project. The project will only be successful if the Chief Executive or the management board, adjusts to the corporate targets, in their attitudes.

"...if the focus of the operation of a company is to be changed so drastically, it should be accompanied with the revision and - if necessary - the restructuring of the staff motivation system. First it should be examined what kind of staff competencies are needed in the new organization. If it is clear, we should examine how we can achieve them, considering, for example, the development of 
appropriate recruitment processes, the career planning of staff as well as the optimized introduction of different - financial and other - motivation tools." [6]

The adequate internal motivation of staff guarantees that they perform their jobs with maximum efficiency. The excellent professional competence of colleagues or merely creating appropriate physical and environmental conditions is not enough.

The internal processes, including the process of client management, will change in the restructured organization.

It is extremely important that the company clearly focuses its CRM implementation, from the very first moment, carefully chooses the segment or the function where the first steps are to be made in order to reach the highest possible returns. Naturally, it should also be considered that the positive experiences connected with the implementation significantly improve the outcome of future projects or the introduction of other functions in other segments within the company. (Figure 1) [8]
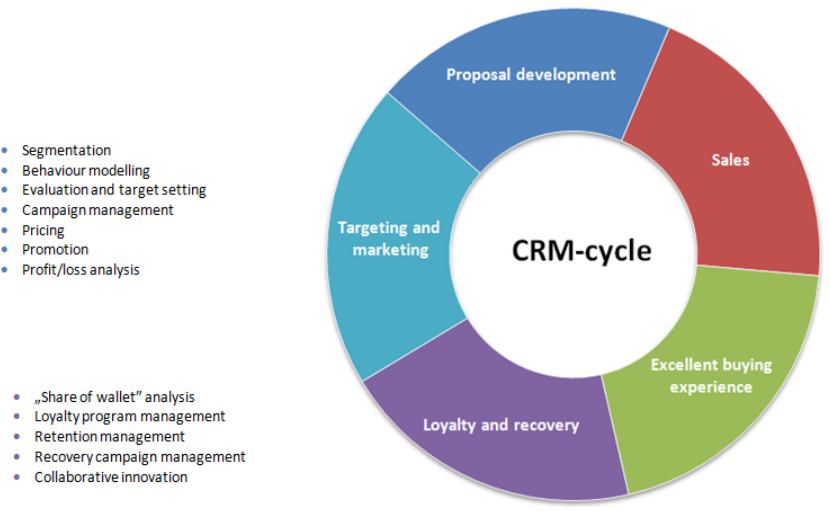

Sales forecast

Figure 1

Customer relationship cycle source: [8]

Büdy discusses ten critical success factors which may have key roles in the introduction of CRM. Among these he puts the definition of functions to be automatized in the first place. The CRM system will not be efficient if the audit is missing or inadequately performed. [3]

According to him, the success factors also include the unconditional attainment of management support, the thoughtful selection of applied technology, the training of users using the system, motivation of staff and appointing the person who are responsible for the operation of the system. 
The operation of every organization - of all sizes - largely depends on its Chief Executive. Thus, the appointment of the head of CRM is also crucial from the aspect of a successful project. The head of the program should be trustworthy and supported by everybody in as much as possible. They should be able to represent the interests of staff and the CRM project alike in the communication with the senior management and should be able to enforce the interests of the company and the CRM project against the subordinate staff. They should make quick and firm decisions and their expertise cannot be questioned.

Tomka and Bögel [11] also regarded it undisputable, that the information technology, significantly contributed to the transformation of knowledge management be in an independent area. But they warn to identify knowledge management with information technology management or IT applications. The knowledge projects cannot be purely information technology projects. In their opinion, these projects can be successful, if the technical and the humanorganizational sides are equally considered.

\section{Organization Development and Management Roles}

A company may regard the development of its organization important for many reasons. It may be exposed to several impacts which cause different changes in the corporate life. These changes, possibly crisis situations may compel the company management to rethink the structure and strategy of the organization. The introduction of a CRM strategy and the development of its information technology support is also such kind of a change in the life of an organization.

According to Tomka and Bögel [11] the most important issue of change management is timing. The experiences prove that people, thus the staff of the organization, too, are reluctant to accept changes. Until they do not feel the danger of losing their job or other factors, they will not be stimulated to change. The change, however, forced by an external pressure might be too late for the organization. An economic crisis, for example, may considerably narrow the room for any maneuvering for the company, thus the number of possibilities will be reduced. Moreover, in an extreme case, like this, the executives of companies will probably invest all their energy into the management of actual problems.

Angyal says that one of the main features of a leader is that they deal with people. Their task is to convince the staff to act and make decisions for the sake of the organization, regardless of their own motivations. [1]

Reviewing the above theories and research, it can be concluded that those companies are successful today where the organization proceeds along a welldefined strategy, the members of the organization are committed and the executives are leader-type personalities with strategic attitudes. 
A company cannot responsibly rely on the decision of one person, in case of such a far-reaching decision. Moreover, the wide range of professional expertise is inevitable not only in the field of information technology, but also in economic and organizational structure, as well as, production technology.

In case of software purchase, the organizational structure of the decision-making group is a team organization which is typically "a task-oriented and autonomous unit consisting of people of different positions from different professional fields of the company. It is set up to carry out temporary or permanent tasks." (Presentation of Dr. Ferenc Nemes, 2009)

The members of the group work towards a common goal during the project. It is worth placing the members of the group in physical proximity to each other for the time of the common work in order to ensure efficient flow of interaction and communication. Naturally, the professional competencies in the team are adjusted to the target of the project. Therefore, our examination aims to survey the qualities of colleagues participating in the implementation as well as their attitudes in connection with CRM information technology implementation.

Our research was carried out with the help of cluster analysis based on principal component analysis.

\section{Cluster Analysis}

Cluster analysis is the whole family of those techniques, which divide large number of respondents into smaller groups, by ensuring the homogeneity of attitudes, experiences, preferences and/or behavior of the group members. [9]

The point in this segmentation method is that the differences between respondents are small within the cluster but the differences between the groups are large.

We tried to form the clusters along the principal components and examined which principal component is accepted or rejected by which segment.

As the result of the principal component analysis, three well-defined components were set up which had special significance for the respondents and belonged together according to their evaluation.

The elements of the strategic principal component included the mapping of corporate maturity, the rationalization of processes, the elaboration of customer management strategy, accurate definition of needs, permanent management support and exact exploration of financial possibilities.

The technological principal component covered the appropriate test run during implementation, the definition of authorization system and the use of faultless database. 
Finally, the elements of the human principal component were the involvement of independent consulting agency, information service to staff, permanent management feedback, continuous supplier system control and customer meetings, exchange of experiences organized by the supplier.

The attitudes of respondents can be examined hereinafter along these components.

The cluster analysis was made with K-Means Cluster process which starts from $\mathrm{K}$ number of predetermined clusters. The program assigns a center point to each cluster and then by using the square of Euclidean distance, those elements are assigned to these centers which are the closest to them. Therefore the groups are formed by the program in a way that they are as far from each other as possible but those in the same cluster are as close to each other as possible. Thus they can be separated easily on the basis of their characteristics.

Table 1

Cluster analysis - cluster centers

\begin{tabular}{|l|c|c|c|}
\hline & \multicolumn{3}{|c|}{ Cluster } \\
\cline { 2 - 4 } & 1 & \multicolumn{1}{|c|}{2} & 3 \\
\hline strategia s1 & -0.60571 & -5.08008 & 0.52909 \\
technologia t1 & -0.59972 & -4.42051 & 0.51585 \\
human h1 & -0.85231 & 0.06744 & 0.64956 \\
\hline
\end{tabular}

Source: own research

Our intention was to determine three clusters along the three principal components, thus the first analysis focused on this. The table of the ultimate cluster centers (Table 1) demonstrates the attitudes of respondents in each cluster.

It is obvious that the group in the $1^{\text {st }}$ cluster rejects all the components while those belonging to the $3^{\text {rd }}$ cluster have a positive attitude to all the components. The members of the $2^{\text {nd }}$ cluster prefer - although weakly - the elements of human component, while they reject the elements of strategic and technological component.

The ANOVA table (Table 2) is not the table of a typical variance analysis. The value of $\mathrm{F}$ indicates the strength of each component in the formation of the cluster. The significance level in this case is 0.005 , when the participation can be regarded significant. 
Table 2

Cluster analysis - ANOVA

\begin{tabular}{|l|r|r|r|r|r|c|}
\hline & \multicolumn{2}{|c|}{ Cluster } & \multicolumn{2}{c|}{ Error } & \multirow{2}{*}{} & \multirow{2}{*}{ Sig. } \\
\cline { 2 - 6 } & Mean Square & df & Mean Square & df & F & Sin \\
\hline strategia s1 & 34.181 & 2 & 0.497 & 132 & 68.738 & 0.000 \\
technologia t1 & 30.313 & 2 & 0.556 & 132 & 54.532 & 0.000 \\
human h1 & 37.102 & 2 & 0.453 & 132 & 81.901 & 0.000 \\
\hline
\end{tabular}

Source: own research

Finally it was examined how many respondents belong to each cluster (Table 3 ). It can be seen that all the respondents could be assigned to one of the groups in the course of the analysis. There is only one respondent in the $2^{\text {nd }}$ cluster, thus this cluster analysis could not be accepted because it would have meant that the human aspect received too much importance. This respondent is considerably different from the others and the variable formed by him is inadequate for further analysis and would distort the result of the examination.

Table 3

Cluster analysis - Number of Cases in each Cluster

\begin{tabular}{|ll|r|}
\hline Cluster & 1 & 58.000 \\
& 2 & 1.000 \\
& 3 & 76.000 \\
Valid & & 135.000 \\
Missing & & 0.000 \\
\hline
\end{tabular}

Source: own research

The analysis was continued by changing the number of clusters on the parameter of cluster analysis. It was expected from this step that the change of cluster figures requires new cluster centers thus the distribution of respondents would be more proportional in the clusters. That one particular respondent, however, had to be placed in an independent cluster again. The checking of this was made by selecting the data file on the basis of the cluster. Since the respondent in the $18^{\text {th }}$ record could not be fit into the cluster structure, he was taken out from the data set with a mark and thereafter the cluster formation was made without him.

The cluster centers created this way are in Table 4. 
Table 4

Final cluster centers

\begin{tabular}{|l|c|c|c|}
\hline & \multicolumn{3}{|c|}{ Cluster } \\
\cline { 2 - 4 } & 1 & 2 & 3 \\
\hline strategia s1 & -0.29956 & -0.60648 & 0.50706 \\
technologia t1 & 0.47076 & -1.28937 & 0.48791 \\
human h1 & -0.97067 & -0.75314 & 0.80623 \\
\hline
\end{tabular}

Source: own research

31 persons, that is $23.1 \%$ of the respondents, are put in the first cluster. 34 people belong to the second cluster, that is $25.4 \%$ of the respondents. The third cluster includes 69 persons, that is $51.5 \%$ of the total number of respondents. All the respondents participating in the analysis were ranked somewhere.

The ANOVA table indicates significant participation in case of all the principal components. The value of $\mathrm{F}$ is the lowest in case of the strategic component which means that this component is the weakest in the cluster formation. It is evident that along the principal components, similar $\mathrm{F}$ values belong to significant difference in two cases out of the three segments while in one case the F value is lower than these. It means that the technological and human components among the dimensions participated in cluster forming to a similar extent while the strategic component had weaker influence on cluster forming. (Table 5)

Table 5

Significance analysis of cluster analysis

\begin{tabular}{|l|r|r|r|r|r|r|}
\hline & \multicolumn{2}{|c|}{ Cluster } & \multicolumn{2}{c|}{ Error } & \multirow{2}{*}{ F } & \multirow{2}{*}{ Sig. } \\
\cline { 2 - 5 } & Mean Square & df & Mean Square & df & F \\
\hline strategia s1 & 16.418 & 2 & 0.574 & 131 & 28.614 & 0.000 \\
technologia t1 & 39.837 & 2 & 0.264 & 131 & 150.661 & 0.000 \\
human h1 & 46.672 & 2 & 0.310 & 131 & 150.402 & 0.000 \\
\hline
\end{tabular}

Source: own research 


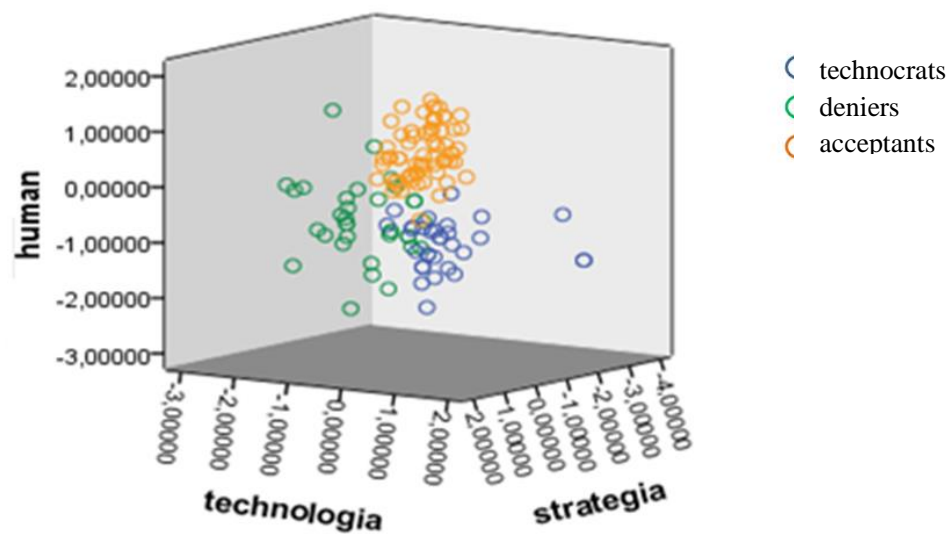

Diagram 1

Cluster depiction - 3D Scatter

Source: own research

The 3D Scatter diagram (Diagram 1) clearly demonstrates the three separate segments. The technocrat respondents are located on the negative side of strategic ( $\mathrm{Z}$ axis), while they are on the positive side from technological aspect ( $\mathrm{X}$ axis). The deniers are grouped in the negative end of all the three axes, while the acceptants are on the positive ends. It is even more obvious from the cluster matrix depiction, where every element describes respondents only in relation to 2 axes at a time. (Diagram 2)

The segments created on the basis of cluster centers can be characterized on the basis of principal components as follows. The respondents belonging to cluster 1 are the technocrats. The technological support and technical background is the most important for them. They strongly deny that human factors may affect success and they do not consider strategic steps important, either, although to a smaller extent. $90.3 \%$ of the members of this cluster are users and only $9.7 \%$ are experts. It is $26.9 \%$ of all the users, that involve IT staff in the selection regardless of the special field of the IT staff. In practice it means that mostly the system administrators got this task. As regards software selection, the key aspect is the comparison of hardware and software elements. These users mostly make decisions by themselves. $85.7 \%$ of them finds the supplier of the chosen software through the internet. 

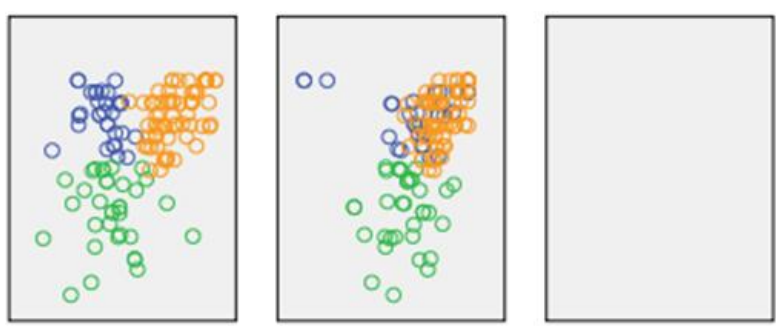

technocrats

$\bigcirc$ deniers

O acceptants
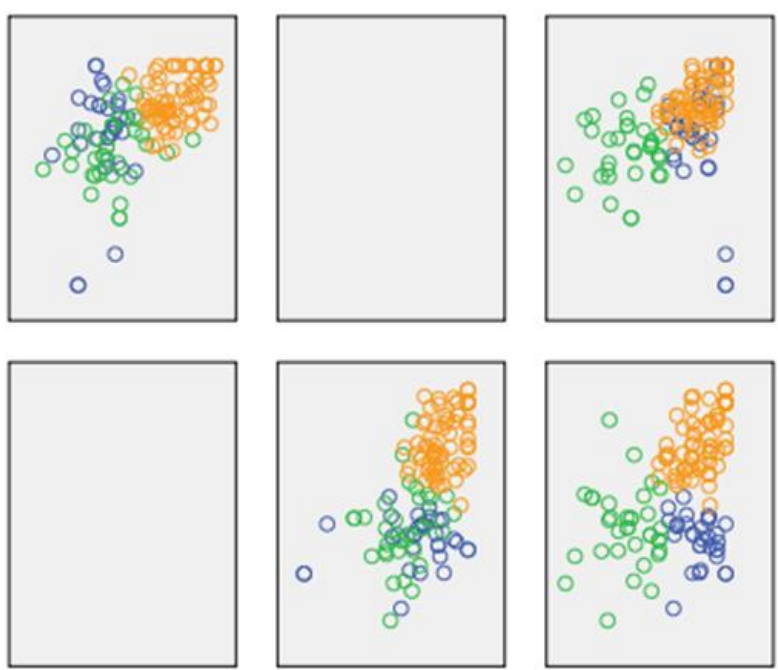

Diagram 2

Cluster matrix

Source: own research

The IT specialists have more information about the actual objectives of the software therefore they are mostly put in the other two clusters. Only $10 \%$ of them belong to this cluster (Table 6). These specialists have a few years of experience and have tracked the implementation of maximum 2 different software packages. They set the success indicator of their implementation projects to a significantly low level and described them as failures in a ratio of $50 \%$ or even higher. 
Table 6

Respondents in the clusters

\begin{tabular}{|c|c|c|c|c|c|}
\hline & & & Respc & ent & \\
\hline & & & 1 & 2 & Total \\
\hline Cluster & 1 & Count & 28 & 3 & 31 \\
\hline & & $\%$ within cluster & $90.3 \%$ & $9.7 \%$ & $100.0 \%$ \\
\hline & & $\%$ within respondent & $26.9 \%$ & $10.0 \%$ & $23.1 \%$ \\
\hline & & $\%$ of Total & $20.9 \%$ & $2.2 \%$ & $23.1 \%$ \\
\hline & 2 & Count & 24 & 10 & 34 \\
\hline & & $\%$ within cluster & $70.6 \%$ & $29.4 \%$ & $100.0 \%$ \\
\hline & & $\%$ within respondent & $23.1 \%$ & $33.3 \%$ & $25.4 \%$ \\
\hline & & $\%$ of Total & $17.9 \%$ & $7.5 \%$ & $25.4 \%$ \\
\hline & 3 & Count & 52 & 17 & 69 \\
\hline & & $\%$ within cluster & $75.4 \%$ & $24.6 \%$ & $100.0 \%$ \\
\hline & & $\%$ within respondent & $50.0 \%$ & $56.7 \%$ & $51.5 \%$ \\
\hline & & $\%$ of Total & $38.8 \%$ & $12.7 \%$ & $51.5 \%$ \\
\hline Total & & Count & 104 & 30 & 134 \\
\hline & & $\%$ within cluster & $77.6 \%$ & $22.4 \%$ & $100.0 \%$ \\
\hline & & $\%$ within respondent & $100.0 \%$ & $100.0 \%$ & $100.0 \%$ \\
\hline & & $\%$ of Total & $77.6 \%$ & $22.4 \%$ & $100.0 \%$ \\
\hline
\end{tabular}

Source: own research

Members of cluster 2 are the resistants. They under-evaluated the features of all the three components. They reject the technological features the most and have similar relation to the other two components, too. $23.1 \%$ of all the users belong to this group, which is $70.6 \%$ representation in the cluster. They probably buy the system, then operate it on a hit or miss basis. They do not make preparations, do not „make it a big deal“. $54.2 \%$ of them consult less then three times before the implementation. They see the solution of all the problems in the introduction of a CRM system. They mostly make their decisions alone - it makes up to $40 \%$ of users belonging to the cluster. Their implementation projects end with failure in most of the cases because the software does not solve their problems, rather create some new ones. These users significantly do not feel the emergence of unexpected costs. $95 \%$ of respondents belonging to this group collected the information from the competitors and introduced the software they saw there thinking that ,if it is good for them, would be good for us, too“. $50 \%$ of the cluster 
members marked easy use as a decisive factor in their choice. $75 \%$ of users belonging here searched the internet and found the supplier there.

$33.3 \%$ of experts were put in this cluster. These experts probably sell software solutions on the market which belong to the so-called solution-in-a-box category and follow the "Take it and use it" principle. The "box" solutions among the cloud-based systems are also in this group. The user support often consists of "mass" courses on one or two occasions where general guidelines for use are given to the purchasers in the frames of a common presentation. They underline the immediate applicability of the software and promise immediate solution by uploading the data in the system. $80 \%$ of these experts participated in the implementation of three or less different softwares and only $20 \%$ of them had 8 10 -year experiences. At least $50 \%$ or more of their implementation projects were successful.

The members of the 3rd cluster are the acceptants. They have a positive attitude towards all the three principal components. Human elements are far the closest to them and they attach similar values to the other two components. 50\% of the users belong to this group which means $75.4 \%$ share in the cluster. They are probably those respondents who try to make decisions after careful preparation but do no weight the tasks and do not set an order of priorities. Their attention is too divided, they may break down due to the diversity of tasks. They are lost in the criteria system of the software selection and finally they decide on the basis of criteria which are not necessarily professional or do not meet their objectives. $50 \%$ of the respondents make team decisions and $60 \%$ of them consult with the supplier more than 3 times before making a choice. $86.4 \%$ of the cluster members significantly indicated the tracking of internal processes as the reason for the investment. They probably regard the internal processes too complicated, but there is a significant dispersion regarding their opinion about the involvement of external consultants. Therefore their implementation projects can also lead to the feeling of failure. $100 \%$ of the cluster members make their decisions on the basis of an offer given by another supplier. $62 \%$ of them reviewed the offers of $2-5$ suppliers, while $15 \%$ collected offers from more than 5 suppliers.

This cluster includes $56.7 \%$ of the experts and presumably, the representatives of medium and large systems also belong here. Those specialists are here who have experiences from the implementation of 4-5 different systems and 55.55\% of those, with 8-10 year experience. They regard the success of their implementation projects significantly good $(\mathrm{p}=0.003)$ and successful, in a ratio of $75 \%$.

\section{Conclusions}

The results of our survey have proven that clearly distinguishable groups can be identified along the factors of preparation and implementation. The differences between the segments can be clearly characterized. The members of each segment were examined on the basis of their role in implementation. Thus, the expert members could be characterized separately on the basis of their success and 
experience, while the members of the purchasing side could be described on the basis of management decision and software selection criteria system.

By reviewing the information system implementations it can be concluded that the introduction of CRM systems was mostly accompanied by the sense of failure both on behalf of the supplier and the purchaser. The number of implementations, however, do not decline, in spite of the fiasco feeling and the experts have hopes for slow growth due to the recovery after the economic crisis. In order to avoid the implementation failure, however, there are some serious tasks to be performed by the supplier as well as the purchaser.

It is very important that the executives of the companies do not regard the purchase and implementation of the system as failure or an "unnecessary waste of money". If the company is not mature enough in terms of organization and/or information system, it is often enough to form a new organizational structure, to apply a well-defined customer strategy in order to make the management feel the positive impacts.

On the basis of our quantitative research it can be concluded that the software supplying side is not fully aware of the motivations and demands of purchasers. The suppliers develop the ideas concerning the customers and hypotheses concerning their decisions on the basis of a general knowledge about consumers.

Our research has proved that the information technology background of purchasers is not adequate. Often the strategic preparedness is also missing for the implementation of the CRM system, therefore the purchasers do not define their needs precisely, they do not set objective criteria system regarding the software to be implemented. The implementation is not treated like a project, the methodological support is expected from the supplier.

In the further part of our examination, principal component analysis was applied for the evaluation of opinion of respondents concerning the preparation and implementation. The importance of each task was evaluated on a scale from 1 to 10, where 1 meant not important at all and 10 was the most important.

The explained variance of principal components was roughly proportional. The results of the survey, of course, cannot be regarded as generalized conclusions for the whole domestic market due to the deficiencies of sampling but the main trends are obvious on the basis of replies received from suppliers and purchasers.

The next step was to examine the ratio of the two responding groups - expert and purchaser - in every cluster. It was concluded that both the experts and the users were represented in all the three clusters. Then, we analyzed what common features can be found regarding the members of groups standing in the two different sides but within one cluster. According to our examination, some of the characteristics of users and experts could be well defined in the three clusters, but there were strong differences between the groups. 
It was proven by our research, that the purchasers, can cope with the lack of serious professional expertise. The methodological deficiencies of suppliers do not help the purchasing companies to solve this problem. Moreover, the supplier side has only a superficial knowledge concerning the motivations and needs of implementing side, therefore the possibly existing methodology does not necessarily put the emphasis on the adequate points. Since we tried to map both sides in our research, we drafted our recommendations separately for the supplier or expert side and separately for the purchaser side.

The outcomes of principal component and cluster analysis have highlighted that the professionals have different attitudes and they regard different areas important. Following the survey of existing staff it is worth setting up expert pairs who can help the implementation projects by complementing each other. Thus, none of the areas will dominate and every task will have an appropriate emphasis.

In regards the purchaser side, the software is selected on the basis of the decision of one person. The disadvantages of this are highlighted by the results of the research. Setting up a professional team would eliminate these drawbacks and the risks of "one-person" decision. The members of the team should be selected on the purchaser side on the basis of the preferences thus it is possible to set up a professional staff who are competent to manage a full implementation project.

The aim of using a CRM system is to classify the information flowing in through different channels and to present the information in a unified way, broken down by customers. Thus, the company is able to define the value of its clients and make the management of primary clients even more efficient. Although the consumption slowly increases due to the economic recovery but it will probably be a slow and lengthy process. The power relationships will change among the economic actors and new centers of gravity will emerge, for example, China or India. There will be a strong battle to keep market share and the emergence of new product categories will be especially important. [2]

These two strategic objectives will definitely target the retention of customers and providing service, at the highest possible standard. Customer relationship marketing and CRM strategy are excellent tools in these efforts, while the information technology support can help to perform efficiently and precisely. The technical knowledge of CRM systems can definitely support the comprehensive realization of customer strategies for companies.

\section{References}

[1] Angyal Á. (1999) A vezetés mesterfogásai, Kossuth Kiadó, Budapest, p. 254

[2] Beinhocher E.-Davis I.-Mendoca L. (2009) Stratégia az új világban, 10 trend, amelyre figyelnünk kell, Harward Business Review XI. évf. 2009/11 pp. $45-51$ 
[3] Büdy L. (2011) A CRM lehetőségei a nagyvállalati gyakorlatban, Marketing \&Menedzsment XXXV. évf. 2001/1 pp. 25-29

[4] Chang W.-Park J. E.-Chaiy S. (2010) How does CRM Technology Transform into Organizational Performance? A Mediating Role of Marketing Capability, Journal of Business Research 2010/63 pp. 849-855

[5] Chikán A. (2003) Vállalatgazdaságtan, AULA Kiadó, Budapest

[6] Erdélyi E.-Kovács. B.-Merényi A.-Számely É. (2006) Experience of the Best Practice in CRM Implementation in Industry, T-Mobile, Telecom Hungary XVII. évf. 2006/3 pp. 16-23

[7] Moorman C.-Rust R.-Bhalla G. (2010) A marketing újragondolása, Harward Business Review XII. évf. 2010/5 pp. 42-50

[8] Rigby D. K.-Ledingham D (2005) A helyes CRM, Harward Business Review VII. évf. 2005/3 pp. 34-43

[9] Scipione P. (1994) A piackutatás gyakorlata, Springer Hungarica Kiadó, Budapest

[10] Szabó-Herman (2014) Productive Entrepreneurship in the EU and Its Barriers in Transition Economies: A Cluster Analysis, Acta Polytechnika Hungarica XI. 2014/6 pp. 73-94

[11] Tomka J.-Bőgel GY. (2010) Vezetés egykor és most, Nemzeti Tankönyvkiadó, Budapest 